\title{
Aleukemic Acute Lymphoblastic Leukemia Cutis
}

National Cancer Institute

\section{Source}

National Cancer Institute. Aleukemic Acute Lymphoblastic Leukemia Cutis. NCI

Thesaurus. Code C5631.

Aleukemic leukemia cutis where the skin in infiltrated by lymphoblasts. 